\title{
Encapsulation of two different TLR ligands into liposomes confer protective immunity and prevent tumor development
}

\author{
Banu Bayyurt ${ }^{\mathrm{a}}$, Gizem Tincer ${ }^{\mathrm{a}, 1}$, Kubra Almacioglu ${ }^{\mathrm{a}}$, Esin Alpdundar ${ }^{\mathrm{b}}$, Mayda Gursel ${ }^{\mathrm{b}}$, Ihsan Gursel ${ }^{\mathrm{a}, *}$ \\ a Thorlab. Therapeutic ODN Research Lab, Department of Molecular Biology and Genetics, Bilkent University, Bilkent, 06800, Ankara, Turkey \\ ${ }^{\mathrm{b}}$ Department of Biological Sciences, Middle East Technical University, 06800, Ankara, Turkey
}

\section{A R T I C L E I N F O}

\section{Article history:}

Received 21 September 2016

Received in revised form 30 December 2016

Accepted 4 January 2017

Available online 7 January 2017

\section{Keywords:}

TLR3

TLR9

Ligands

Immunoadjuvant

Liposomes

Immune response

Preventive cancer vaccine

\begin{abstract}
A B S T R A C T
Nucleic acid-based Toll-like receptor (TLR) ligands are promising adjuvants and immunotherapeutic agents. Combination of TLR ligands potentiates immune response by providing synergistic immune activity via triggering different signaling pathways and may impact antigen dependent T-cell immune memory. However, their short circulation time due to nuclease attack hampers their clinical performance. Liposomes offer inclusion of protein and nucleic acid-based drugs with high encapsulation efficiency and drug loading. Furthermore, they protect cargo from enzymatic cleavage while providing stability, and enhancing biological activity. Herein, we aimed to develop a liposomal carrier system co-encapsulating TLR3 (polyinosinic-polycytidylic acid; poly(I:C)) and TLR9 (oligodeoxynucleotides (ODN) expressing unmethylated $\mathrm{CpG}$ motifs; $\mathrm{CpG} \mathrm{ODN}$ ) ligands as immunoadjuvants together with protein antigen. To demonstrate that this depot system not only induce synergistic innate immune activation but also boost antigendependent immune response, we analyzed the potency of dual ligand encapsulated liposomes in long-term cancer protection assay. Data revealed that $\mathrm{CpG}$ ODN and poly $(\mathrm{I}: \mathrm{C})$ co-encapsulation significantly enhanced cytokine production from spleen cells. Activation and maturation of dendritic cells as well as bactericidal potency of macrophages along with internalization capacity of ligands were elevated upon incubation with liposomes co-encapsulating CpG ODN and poly(I:C). Immunization with co-encapsulated liposomes induced OVA-specific Th1-biased immunity which persisted for eight months post-booster injection. Subsequent challenge with OVA-expressing tumor cell line, E.G7, demonstrated that mice immunized with liposomes co-encapsulating dual ligands had significantly slower tumor progression. Tumor clearance was dependent on OVA-specific cytotoxic memory T-cells. These results suggest that liposomes co-encapsulating TLR3 and TLR9 ligands and a specific cancer antigen could be developed as a preventive cancer vaccine.
\end{abstract}

(C) 2017 Elsevier B.V. All rights reserved.

\section{Introduction}

Innate immune cells recognize microbial (bacterial and viral) components via pattern recognition receptors (PRRs) through pathogen-associated molecular patterns (PAMPs) and differentiate self from nonself [1,2]. Toll-like receptors (TLRs) are the most extensively studied PRRs. TLR family members are sub-divided to cell membrane-associated and endosome-associated receptors. Endosomal TLRs are specialized to sense nucleic acids. While TLR3 and TLR7/8 recognizes double and single-stranded RNA, TLR9 recognizes bacterial DNA or single-stranded synthetic oligodeoxynucleotides (ODN) expressing unmethylated $\mathrm{CpG}$ motifs (CpG ODNs hereafter) [3-6]. Multiple TLR triggering could synergistically activate immune response upon multiple agonists engagement [7].

\footnotetext{
* Corresponding author.

E-mail address: ihsangursel@bilkent.edu.tr (I. Gursel).

1 Present address: German Centre for Neurodegenerative Diseases (DZNE) Dresden within Helmholtz Association, Arnoldstr. 18, 01307 Dresden, Germany.
}

CpG ODNs, which are found frequently in bacterial and viral genome but rare in mammalian DNA, enhances innate immune response. Among different ODN classes, D-ODNs (also known as CpG-A type) synthesized as a mixed backbone ODN contain purine/pyrimidine/CpG/purine/pyrimidine motif and poly G-tail at both ends. This ODN type induces secretion of type I interferons (IFNs) from plasmacytoid dendritic cells (pDCs), and IFN- $\gamma$ from natural killer (NK) cells $[8,9]$. It activates nuclear factor kappa $\mathrm{B}(\mathrm{NF}-\kappa \mathrm{B})$ and interferon regulatory factor 7 (IRF7) via myeloid differentiation primary response gene 88 (MyD88) dependent pathway. Polyinosinic-polycytidylic acid (poly(I:C) hereafter), a synthetic analog of double-stranded RNA initiates signaling cascade through TLR3 and induces type I IFNs along with proinflammatory cytokines mediated by NF- $\kappa$ B and IRF3 via TRIF-dependent (MyD88-independent) pathway [3,6,10]. Both TLR ligands trigger anti-viral and anti-bacterial immune responses and mimic viral and bacterial infections. The simultaneous sensing of these two endosomal TLR ligands by PRRs boosts innate immune response in a synergistic manner and leads to more pronounced type I IFNs [11], proinflammatory cytokines, and nitric oxide production [12] with elevated cytotoxic T 
lymphocyte (CTL) activity $[13,14]$. When delivered together these ligands may help to improve better antigen dependent immunity and antitumor activity [15]. Nucleic acid-based TLR ligands are promising candidates as type 1T helper cell (Th1) specific vaccine adjuvants [8, 16], anti-cancer [17] or anti-allergic therapeutic agents [18], however, when given in non-encapsulated forms, their clinical performance is hampered mainly due to in vivo degradation by nucleases or rapid clearance by serum protein adsorption [19]. To overcome this problem, several strategies were proposed such as polymer-based nanoparticles $[20,21]$, polysaccharide complexes [22], liposomes [23-25] aiming to protect these labile molecules until they reach their target cells upon administration. In our previous studies, we have demonstrated that encapsulation of TLR ligands within liposomes not only increases their stability and protects them from digestion but also enhances their immunostimulatory and immunotherapeutic breadth $[24,26]$. The present work, aims to extend our previous experience and planned to co-encapsulate dual TLR ligands (CpG ODN and poly(I:C)) in liposomes and test their vaccine potency leading to long-term prevention against cancer. We provide evidence that dual ligand encapsulating liposomal vaccine improved ligand internalization, enhanced APC function, promoted a strong Th1-biased antigen-specific immune response and subsequently prevented animals to develop tumors eight months after immunization. We also demonstrated that the dual ligand co-encapsulating liposomal vaccine induce a long-lasting antigen specific $\mathrm{CD}^{+}$memory T-cell immunity, critically contributing tumor clearance of immunized mice.

\section{Materials and methods}

\subsection{Reagents}

Cholesterol (Chol) and L- $\alpha$-phosphatidylcholine (PC), lipids that were used in liposomes preparation was purchased from Sigma Aldrich (St. Louis, MO, USA) and Avanti Polar Lipids (Alabaster, AL, USA), respectively. TLR9 ligand, CpG ODN D35 5'-GGtgcatcgatgcaggggGG-3' was kindly provided by Dr. Ken Ishii (IFReC, Japan) [27]. Bases shown in capital letter have phosphorothioate linkage and those in lower case have phosphodiester linkages. CpG motif is underlined. Cy5-labeled CpG ODN was synthesized in CBER/FDA core Facility and provided by Dr. Dennis M. Klinman TLR3 ligand poly(I:C) was from Amersham (Piscataway, NJ, USA) and fluorescein labeled poly(I:C) was from Invivogen (Toulouse, France).

All cell culture media components were from Gibco (NY, USA) and Lonza (Lonza, Walkersville, MD, USA). Cytokine ELISA reagents: recombinant cytokines, monoclonal unlabeled and biotinylated antibodies against mIL-6, mIL-12 and mTNF- $\alpha$ were purchased from Biolegend (San Diego, CA, USA), while streptavidin-alkaline phosphatase, hIFN- $\alpha$ and mIFN- $\gamma$ were purchased from Mabtech (Cincinnati, OH, USA) and hIP10 was from BD (San Jose, CA, USA). P-nitrophenyl phosphate disodium salt substrate (PNPP) was purchased from Thermo Scientific (San Jose, CA, USA). Immunoglobulin ELISA reagents; goat anti-mouse total IgG, IgG1, IgG2c, and monoclonal antibodies conjugated with alkaline phosphatase (AP) were from Southern Biotech (Birmingham, AL, USA). FACS antibodies conjugated to fluorescent chromophores were obtained from Biolegend. B16-Blue IFN- $\alpha / \beta$ cells that allow the detection of bioactive murine type I IFNs were obtained from Invivogen and used according to the manufacturer's protocol.

\subsection{Methods}

\subsubsection{Preparation of liposomes}

Phospholipid stocks were prepared in chloroform and stored at $-20{ }^{\circ} \mathrm{C}$ until use. Liposomes were prepared as described earlier [24, 26]. Briefly, lipids (PC:Chol, 1:1 molar ratio, $20 \mu \mathrm{mol}$ total lipid in $2 \mathrm{ml}$ chloroform) were mixed and film was formed using rotary evaporator (ILMVAC, Ilmenau, Germany). Vesicles were generated by hydrating film with $1 \times$ PBS. These were sonicated five times for $30 \mathrm{~s}$ on and $30 \mathrm{~s}$ off at $4{ }^{\circ} \mathrm{C}$ using a Vibra Cell Sonicator (Sonics and Materials, Danbury, CT, USA) to generate smaller unilammellar vesicles (SUV).

Ligand loading within lipid vesicles were performed as described earlier [24,26]. Briefly, ligands (1 $\mathrm{mg}$ of each ligand) and preformed SUVs $(20 \mu \mathrm{mol})$ were mixed and snap frozen in liquid nitrogen, and freeze-dried overnight (VirTis benchtop K, Bieleveld, Germany). Dried lipid/ODN mixture was rehydrated (1/10 initial volume) using nuclease-free $\mathrm{ddH}_{2} \mathrm{O}$ and vortexed for $15 \mathrm{~s}$ every $5 \mathrm{~min}$ for $30 \mathrm{~min}$ at room temperature. Equal volume of PBS was added to the mixture to adjust the tonicity of the resulting liposomes. Liposomes were washed twice with $1 \times$ PBS (pH: 7.4) to remove the unloaded molecules and centrifuged at $16000 \mathrm{~g}$ for $1 \mathrm{~h}$. Final concentration of liposomes is $20 \mu \mathrm{M}$ lipid/mg ligand. Liposome formulations were stored at $4{ }^{\circ} \mathrm{C}$ until use.

\subsubsection{In vitro stimulation}

Splenocytes isolated from wild type C57BL/6 mice by mashing spleen with syringe plunger were seeded at $2 \times 10^{6} \mathrm{cell} / \mathrm{ml}(250 \mu \mathrm{l})$ on 96-well cell culture plates and stimulated with non- or liposome-encapsulated CpG ODN or poly(I:C) or their combinations $(2 \mu \mathrm{g} / \mathrm{ml}$ per ligand; $20 \mu \mathrm{mol} \mathrm{lipid} / 1 \mathrm{mg}$ ligand) for $36 \mathrm{~h}$ at $37^{\circ} \mathrm{C}$ in a $5 \% \mathrm{CO}_{2}$ incubator. After stimulation, supernatants were collected. mIL- 6 and mIFN- $\gamma$ secretion was analyzed by ELISA. Additionally, IFN- $\alpha / \beta$ was assessed using B16-Blue IFN- $\alpha / \beta$ reporter cells as described previously [28]. For uptake and binding experiments, splenocytes were incubated at $37{ }^{\circ} \mathrm{C}$ with labeled non-encapsulated ligands or liposomes encapsulating fluorescein-labeled poly(I:C) and/or Cy5-labeled CpG ODN for 2 h. CpG ODN and/or poly $(\mathrm{I}: \mathrm{C})$ positive cells were recorded using BD Accuri C6 flow cytometer. Cell viability was assessed using cell counting kit-8 (CCK-8, Dojindo, Kumamoto, Japan) according to the manufacturer's protocol.

All human peripheral blood mononuclear cell (hPBMC) experiments were conducted following approval from the Bilkent University Human Studies Ethical Committee (Approval \#: BILHSEC NO:2014-09-02-02) and with the informed consent of all participants. hPBMCs collected from healthy donors and purified using Ficoll density centrifugation were seeded at $1 \times 10^{6} \mathrm{cell} / \mathrm{ml}(200-250 \mu \mathrm{l})$ on 96-well cell culture plates. Cells were stimulated for $24 \mathrm{~h}$. After incubation, supernatants were collected and used to detect hIP-10 and hIFN- $\alpha$ via ELISA and cells were stained with fluorescent-labeled anti-CD83 and anti-HLADR, and analyzed by flow cytometry.

RAW 264.7 macrophage cell line $\left(0.5 \times 10^{6} \mathrm{cell} / \mathrm{ml}\right)$ was stimulated with non-encapsulated or liposome-loaded CpG ODN or poly(I:C) or their combinations ( $2 \mu \mathrm{g} / \mathrm{ml}$ per ligand; $20 \mu \mathrm{mol}$ lipid/1 mg ligand) and TNF- $\alpha$ level was analyzed via ELISA.

Antigen processing was analyzed addition of non-encapsulated or co-encapsulating ligands ( $2 \mu \mathrm{g} / \mathrm{ml}$ per ligand; $20 \mu \mathrm{mol} \mathrm{lipid} / 1 \mathrm{mg} \mathrm{li-}$ gand) together with $\mathrm{DQ}^{\mathrm{TM}}-$ Ovalbumin $\left(2 \mu \mathrm{g} / \mathrm{ml}, \mathrm{DQ}^{\mathrm{TM}}-\mathrm{OVA}\right.$, Molecular Probes) into APCs $\left(0.5 \times 10^{6}\right.$; BM-DCs, BM-DMs and RAW cells $)$. After $6 \mathrm{~h}$ incubation, fluorochrome released upon proteolytic processing were analyzed by flow cytometry

\subsubsection{Generation and stimulation of bone marrow-derived dendritic cells (BM-DCS) and macrophages (BM-DM)}

BM-DCs were generated from bone marrow isolated from the femur and tibia of C57BL/6 mice incubating with GM-CSF and IL-4 as described previously [29]. The 6-8-day old immature BM-DCs $\left(1 \times 10^{6} \mathrm{cell} / \mathrm{ml}\right)$ were stimulated with non-encapsulated or liposomes $(20 \mu \mathrm{M}$ lipid/mg

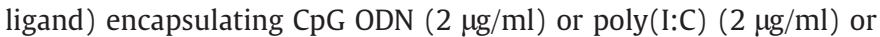
their $1: 1$ combination at $37{ }^{\circ} \mathrm{C}$ in a $5 \% \mathrm{CO}_{2}$ incubator. Following $24 \mathrm{~h}$ of incubation, the supernatants were collected and used for measurement of cytokines by ELISA and by B16-Blue IFN- $\alpha / \beta$ reporter cells. The expression levels of CD11b, CD11c, MHC-II, CD80 and CD86 in BM-DCs was analyzed by flow cytometry. Generated BM-DCs were approximately $80 \% \mathrm{CD}_{11} \mathrm{~b}^{+} / \mathrm{CD} 11 \mathrm{c}^{+}$double positive (Fig. S1A). In addition, propidium iodide (PI) staining was performed to analyze cell viability of stimulated BM-DCs. 
BM-DMs were generated from bone marrow isolated from the femur and tibia of C57BL/6 mice incubated with 30\% L929-conditioned medium (L929-CM) for 6 days. BM-DMs $\left(0.5 \times 10^{6} \mathrm{cell} / \mathrm{ml}\right)$ were stimulated with non-encapsulated or liposome-encapsulated CpG ODN or poly(I:C) or their combinations $(0-18 \mu \mathrm{g} / \mathrm{ml}$ from each ligand, $20 \mu \mathrm{M}$ lipid/mg ligand) and supernatants were used for nitric oxide (NO) analysis via Griess reagent (Sigma, St. Louis, MO, USA) and cytokine ELISA.

\subsubsection{Immunization study}

Animals were kept in the animal holding facility of the Department of Molecular Biology and Genetics at Bilkent University under controlled ambient conditions $\left(22 \pm 2{ }^{\circ} \mathrm{C}\right)$ regulated with $12 \mathrm{~h}$ light and $12 \mathrm{~h}$ dark cycles. They were provided with unlimited access of food and water. All animal studies were conducted with prior approval of the animal ethics committee of Bilkent University (Approval \#: BILAEC NO:2014/32).

Female C57BL/6 mice (6-8 week old) were injected twice intraperitoneally (i.p.) two weeks apart with non-encapsulated or encapsulated CpG ODN or poly(I:C) (10 $\mu$ g each ligand $0.20 \mu \mathrm{mol}$ liposomes/injection) or their 1:1 combination plus ovalbumin (OVA, $5 \mu \mathrm{g} /$ injection). Blood was collected from tail vein of mice at 1 st and 8 th month after booster injection. IgG subtypes were analyzed by end-point ELISA from collected sera with proper titrations of each samples.

At the end of eight month post-booster injection, animals were subcutaneously inoculated with $4 \times 10^{6}$ E.G7-OVA thymoma cells (EL4 cells stably expressing OVA, ATCC) which were cultured in complete medium containing G418 ( $1 \mu \mathrm{g} / \mathrm{ml})$ before injection. Tumor size was measured daily by digital caliper and recorded for 14 days. Then, animals were euthanized and spleens were recovered to isolate splenocytes. IFN- $\gamma$-producing CD8 ${ }^{+}$T-cells against SIINFEKL peptide were determined by ELISPOT assay.

\subsubsection{ELISA and ELISPOT assays}

Immulon $2 \mathrm{HB}$ or 1B microtiter plates (Thermo Scientific, San Jose, CA, USA) were coated with anti-cytokine or anti-IgG antibodies (Ab), respectively, and then blocked with PBS-BSA. Serially diluted standards and culture supernatants or serially diluted mouse sera were added to plates for overnight at $4{ }^{\circ} \mathrm{C}$. Cytokine was detected using biotinylated anti-cytokine $\mathrm{Ab}$ followed by phosphatase-streptavidin whereas bound IgG subclasses were detected using alkaline phosphatase streptavidin-conjugated anti-IgG antibodies and developed by the addition of PNPP substrate.

Anti-IFN- $\gamma$ Ab coated Immulon $2 \mathrm{HB}$ plates were blocked with PBSBSA in ELISPOT assay. Splenocytes were serially diluted and seeded to pre-coated plates either with SIINFEKL supplemented (SIINFEKL:OVA 257-264 peptide, Anaspec Inc., San Jose, CA, USA) or just media containing wells. Cells were incubated for further $18 \mathrm{~h}$ at $37^{\circ} \mathrm{C}$ in a $5 \% \mathrm{CO}_{2}$ incubator. IFN- $\gamma^{+} \mathrm{CD} 8^{+} \mathrm{T}$ cell spots were detected using biotinylated anti-IFN- $\gamma$ Ab followed by alkaline phosphatase streptavidin and BCIP dissolved in low melting agarose solutions (Prona, Reducta, Poland; 1/ $4, v / v)$. Spots were counted under binocular stereo microscope.

\subsubsection{Statistical analysis}

Statistical significant differences between groups were determined using one-way or two-way ANOVA following Tukey's or Bonferroni post-hoc comparison and Student's t-test analysis using GraphPad Prism software (version 5, San Diego, CA, USA). P-values $<0.05$ were considered as significant.

\section{Results}

3.1. IL-6 and interferon type I/II productions were synergistically enhanced by co-encapsulating poly(I:C) and $\mathrm{CpG} O \mathrm{ODN}$ in neutral liposomes

Our main aim was to combine and enhance the synergistic immunostimulatory activity of the two nucleic acid-based TLR ligands known to trigger MyD88 and TRIF dependent signaling cascades by co-encapsulating them in liposomes thereby achieving simultaneous ligand delivery to innate immune cells. The prospect of this approach was assessed by incubating splenocytes either with non-encapsulated or encapsulated poly(I:C) and CpG ODN at $2 \mu \mathrm{g} / \mathrm{ml}$ dose of each ligand. Data implied that, co-encapsulating poly(I:C) and CpG ODN significantly increased both IL- 6 and IFN- $\gamma$ and IFN- $\alpha / \beta$ levels over either non-encapsulated alone, non-encapsulated dual combined or separately encapsulated ligands ( $p<0.05$, one-way ANOVA, Tukey's HSD post hoc test, Fig. $1 \mathrm{~A}-\mathrm{C}$ ). To rule out the toxicity of ligand stimulation on spleen cells, proliferation assay was conducted using Cell Counting Kit-8. Results revealed that there was no significant difference between groups (one-way ANOVA, Tukey's HSD Fig. 1D).

Next, ex vivo immunostimulatory potential of dual TLR ligand co-encapsulated liposomes were checked following i.p. injection to C57BL/6 mice (Fig. 1E). Four hours after i.p. treatment, spleen cells were incubated for further $24 \mathrm{~h}$ in cell culture with no additional stimulation and costimulatory (CD86) molecule expressions were analyzed by flow cytometry. Even though the injected initial amounts of non-encapsulated ligands were 2.5 fold more ( $25 \mu \mathrm{g}$ each ligand) than the dual ligandloaded liposomal group (10 $\mu$ g each ligand), cells that received liposomal poly(I:C) plus CpG ODN surpassed non-encapsulated combination response in terms of CD86 upregulation (Fig. 1E). Of note, $10 \mu \mathrm{g}$ injection of each non-encapsulated ligands did not initiate any detectable CD86 upregulation. These findings revealed that only liposomes co-encapsulating both TLR ligands are potent immune inducers than their i) single or ii) dual non-encapsulated ligand counterparts both in culture and upon in vivo administration.

\subsection{Liposomes co-encapsulating TLR3 and TLR9 ligands enhanced APC function}

Upregulation of MHC class II as well as co-stimulatory molecules along with cytokine production is a direct evidence of improved APC activity/function. We next assessed the potential of liposomes co-encapsulating poly(I:C) and CpG ODN for cellular activation and maturation of antigen presenting cells (APCs). We found that indeed liposome formulations mediate superior effect than the non-encapsulated ligand treatments. BM-DCs were generated in the presence of GM-CSF and IL-4 for six days in culture. Following harvest they were incubated with non-encapsulated or liposome-loaded TLR ligands. After $24 \mathrm{~h}$ cells were fixed and the number of $\mathrm{CD} 11 \mathrm{c}^{+} \mathrm{BM}-\mathrm{DC}$ positive for MHCII, CD86 or CD80 was determined by flow cytometry. Our cell gating strategy throughout these investigations is presented in Fig. S1B. When the surface marker upregulation levels of non-encapsulated and liposome-loaded single $\mathrm{CpG}$ ODN or poly(I:C) groups were analyzed there were no significant difference (Fig. S1C). Strikingly, when TLR3 and TLR9 ligands were co-encapsulated within liposomes, it led to significantly higher levels of co-stimulatory molecule (CD80 and CD86) upregulation (Fig. 2A-B and Fig. S1D-E). According to three independent experiments, $\mathrm{MHC}^{-\mathrm{II}^{+}} / \mathrm{CD} 6^{+}$double positive $\mathrm{CD} 11 \mathrm{c}^{+} \mathrm{BM}-\mathrm{DC}$ was higher in co-encapsulated group $(74.0 \pm 2.0 \%)$ than non-encapsulated or liposome-loaded poly(I:C) $(57.5 \pm 2.6 \%$ and $55.0 \pm 1.5 \%$, respectively) or non-encapsulated or liposome-encapsulated CpG ODN ( $30.5 \pm 2.0 \%$ and $35.0 \pm 2.0 \%$, respectively) or their separately encapsulated combination $(62.5 \pm 3.5 \%)$ (Fig. $2 \mathrm{~A})$. This data suggested that when dual ligands were encapsulated within liposomes higher MHC$\mathrm{II}^{+} / \mathrm{CD} 6^{+}$double positive BM-DCs population were obtained compared to non-encapsulated ligand combination treated BM-DCs (Fig. 2B). Of note, in order to rule out that ligand treatments induce non-specific cell death, at the end of stimulation, cell viability was analyzed using PI staining and no significant difference between groups were observed (one-way ANOVA, Tukey's HSD, $p<0.05$; Fig. S1F).

When, IL-12 production, a cytokine known to skew immune response towards Th1 from BM-DCs in response to ligand treatments was analyzed from cell supernatants after treatment, we detected that dual ligand co-encapsulated group generated six fold more IL-12 from 

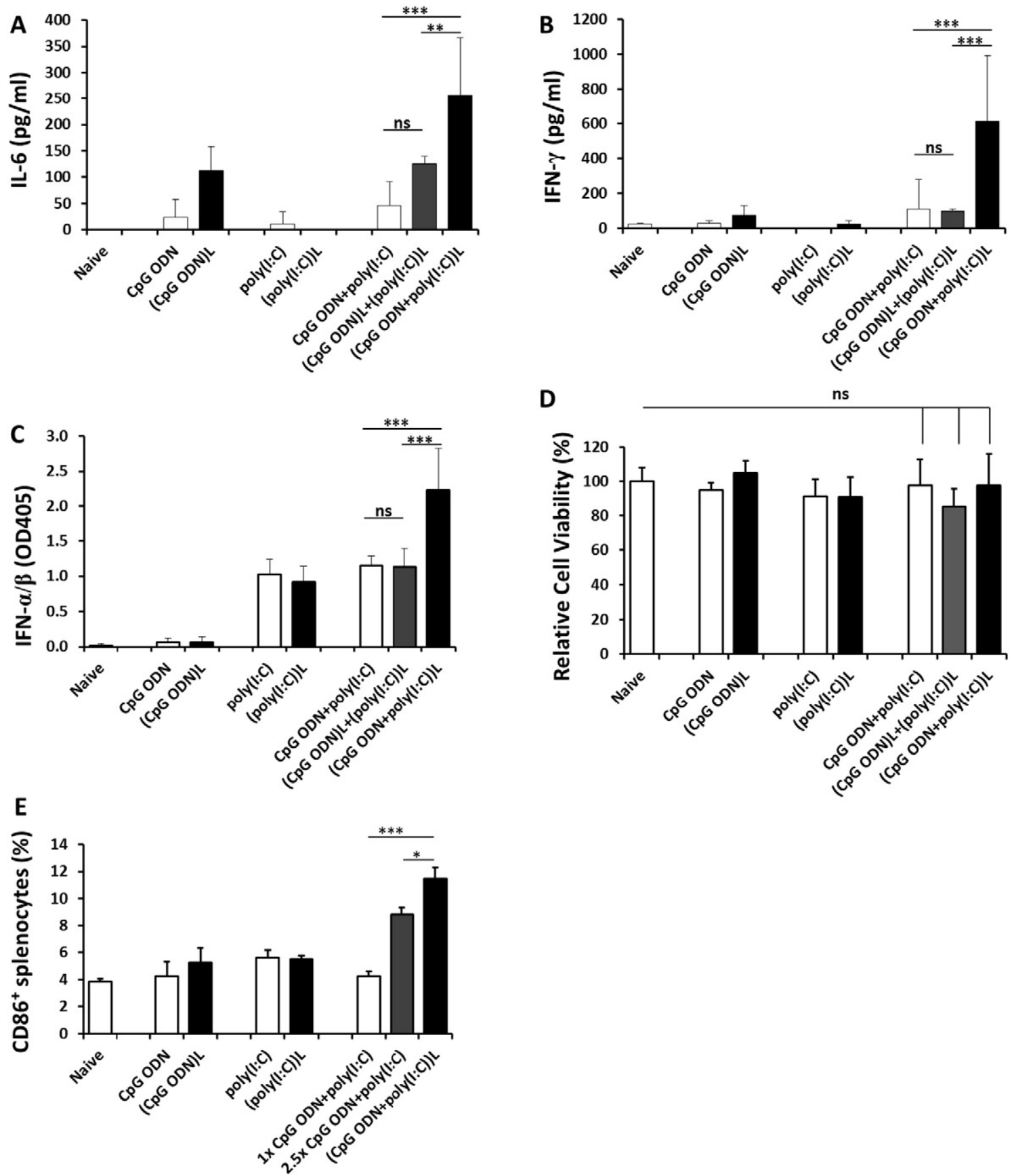

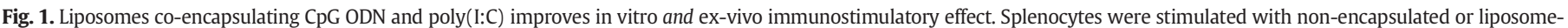

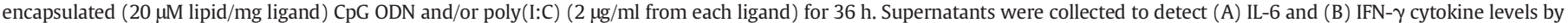

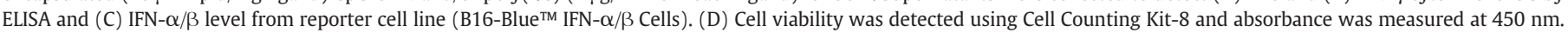

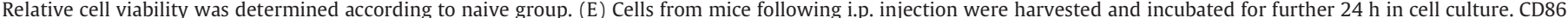

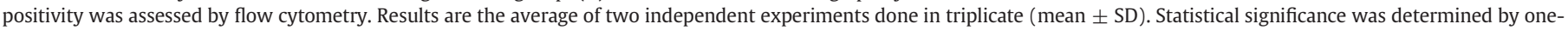
way ANOVA followed by Tukey's (HSD) test. ns: non-significant; ${ }^{*} p<0.05 ;{ }^{* *} p<0.01 ;{ }^{* * *} p<0.001$.

the supernatants, whereas separately encapsulated ligands yielded only $\sim 4$ fold more IL-12 over non-encapsulated ligand combination treated groups (Fig. 2C). Furthermore, type I IFN secretion from BM-DCs treated with co-encapsulated $\mathrm{CpG}$ ODN plus poly(I:C) was found to be $\sim 2.0$ fold and $\sim 1.7$ fold more compared to non-encapsulated combination treated group and separately encapsulated $\mathrm{CpG}$ ODN and poly(I:C) group, respectively (Fig. 2D).

In a separate experiment, bone marrow derived macrophages (BM$\mathrm{DM})$ were generated and incubated with non-encapsulated or liposomes co-encapsulating ligands for $24 \mathrm{~h}$. Nitric oxide (NO), and IL-12 levels were determined by Griess reagent, ELISA, respectively. While
IL-12 production in co-encapsulating group, (CpG ODN + poly $(\mathrm{I}: \mathrm{C})) \mathrm{L}$, was consistently higher than non-encapsulated combination at all doses except at $18 \mu \mathrm{g} / \mathrm{ml}$ dose, NO production was elevated only in coencapsulated group at 18 and $6 \mu \mathrm{g} / \mathrm{ml}$ doses (Two-way ANOVA, Bonferroni; Fig. $3 \mathrm{~A}$ and B). Moreover, 2 fold more TNF- $\alpha$ production was detected from (CpG ODN + poly(I:C))L treated cells (Fig. 3C).

Effective antigen presentation could only be achieved when both antigen and adjuvant simultaneously internalized by APCs. Liposomes are excellent candidates for simultaneous delivery of their cargo. To address this, $\mathrm{DQ}^{\mathrm{TM}}-\mathrm{OVA}$, was used either with non-encapsulated or with dual ligand co-encapsulated liposomes. $\mathrm{DQ}^{\mathrm{TM}}-\mathrm{OVA}$ is an ovalbumin protein 
A
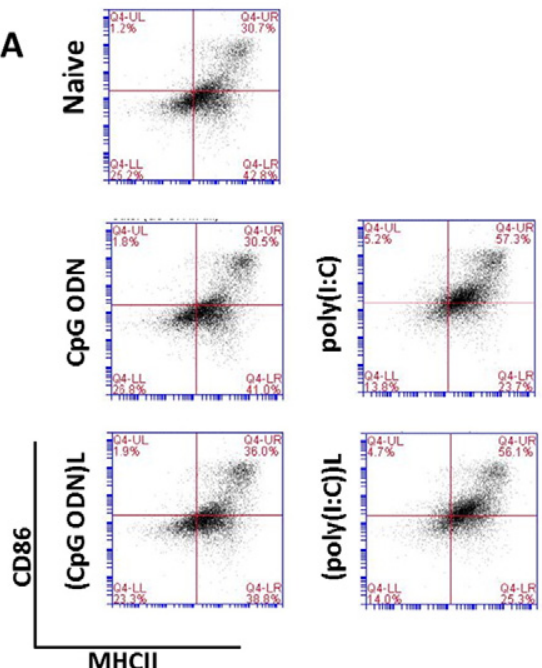

B

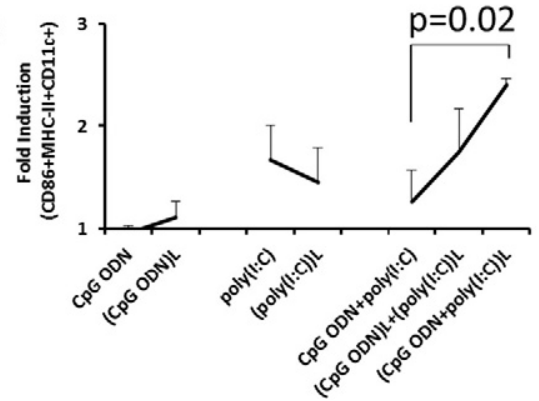

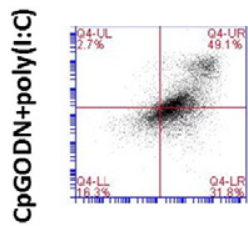
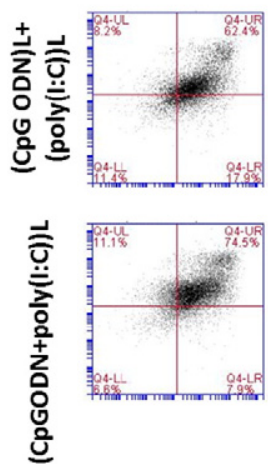

C

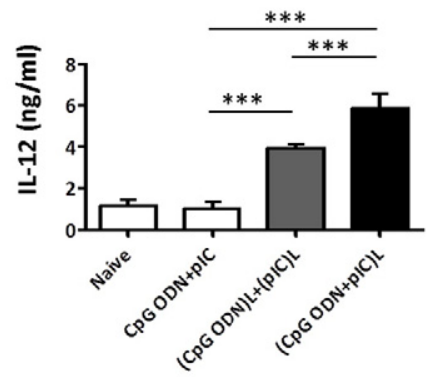

D

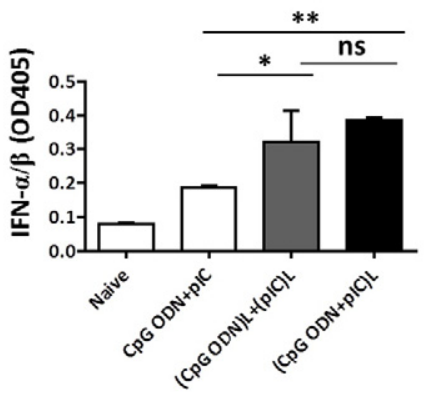

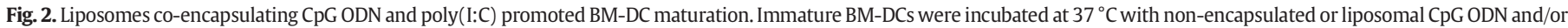

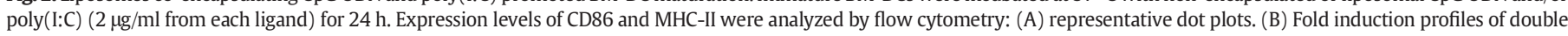

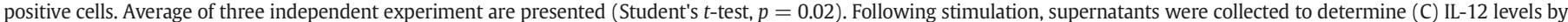

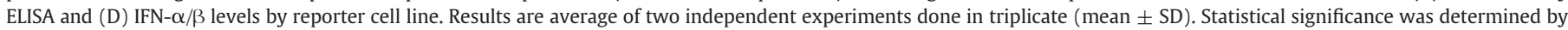
ANOVA followed by Tukey's (HSD) test. ns: non-significant; ${ }^{*} p<0.05 ;{ }^{* *} p<0.01 ;{ }^{* * *} p<0.001$.

conjugated to a pH insensitive self-quenching dye. Upon internalization, fluorescence could be detected when ovalbumin is hydrolyzed. We assessed antigen delivery and processing ability of liposomal constructs following incubation with BM-DC, BM-DM and RAW 264.7 cells (Fig. 3D). All data was normalized to degradation level of each treatment group incubated at $4{ }^{\circ} \mathrm{C}$. We found that $6 \mathrm{~h}$ after incubation, fluorescence signal was significantly high for liposome treated cells compared to non-encapsulated ligand treated cells ( $t$-test, $p<0.001$ ).

When the findings from Figs. 2 and 3 were taken together, liposomes co-encapsulating CpG ODN and poly(I:C) i) induced robust cytokine production, ii) magnified bactericidal activity, iii) upregulated costimulatory molecules, and iv) improved APC function.

3.3. Co-encapsulation of poly(I:C) and CpG ODN within liposomes augmented ligand binding by immune cells

The mechanism of the enhanced synergistic innate immune activation could be due to effective internalization of liposomal ligands by the target cells.

To verify whether augmented immune activity correlated with the improved cellular uptake, non-encapsulated and liposomal forms of Cy5-labeled CpG ODN and fluorescein-labeled poly(I:C) ligands were used to stimulate mouse immune cells and ligand specific flurochrome positivity was analyzed by flow cytometry (Fig. 4). After $2 \mathrm{~h}$ incubation, non-encapsulated dual ligand treated cells had 5.2\% and 1.3\% (for $\mathrm{CpG}$ ODN and poly(I:C) signal, respectively) positivity, whereas dual ligand co-encapsulated treatment gave $12.5 \%$ and $6.5 \% \mathrm{CpG}$ ODN and poly $(\mathrm{I}: \mathrm{C})$ positivity, respectively (Fig. 4A). Consequently, co-encapsulation by liposomes provided $\sim 2.5$ fold more $\mathrm{CpG}$ ODN and $\sim 5$ fold more poly(I:C) binding. When relative MFI values of the treatments were analyzed, this improvement in ligand binding was more pronounced (Fig. 4B). Thus, the improved uptake ability of both ligands via liposome encapsulation led to a robust synergistic immune activity. Furthermore, this finding revealed that rather than encapsulating TLR3 and TLR9 ligands in different liposomes, co-encapsulating them within a single carrier is more preferable (Fig. 4C).

3.4. Antigen loading together with dual TLR ligands within liposomes provides magnified and sustained antigen specific IgG response

After observing that poly(I:C) and CpG ODN co-encapsulated within liposomes boosted Th1-biased immune activation and improved APC function, we next investigated the potential of this system as a preventive vaccine (Fig. 5A). After injecting C57BL/6 mice twice (primary @ d:0 and booster @ d:14) with indicated formulations (Fig. 5B), sera were collected from animals following tail bleedings and anti-OVA IgG levels were detected by end-point ELISA. Serum titrations for total IgG, IgG1 and IgG2c subtypes were analyzed following 1 st and the 8th month post-booster injections (Fig. 5B-D). The rationale of the immunization study was to identify anti-OVA antibody persistence among groups. As seen in Fig. 5B, (CpG ODN + OVA $) \mathrm{L}+($ poly $(\mathrm{I}: \mathrm{C})+\mathrm{OVA}) \mathrm{L}$ and $(\mathrm{CpG}$ ODN + poly $(\mathrm{I}: \mathrm{C})+\mathrm{OVA}) \mathrm{L}$ groups gave the highest total IgG titers at the end of eight months post-booster injection. If one expects to raise a Th- 1 biased anti-OVA immunity upon immunization, the vaccine candidate should reduce IgG1 and promote IgG2c (or IgG2a in Balb/c mice). When our results by the end of eight months of antibody titer is 

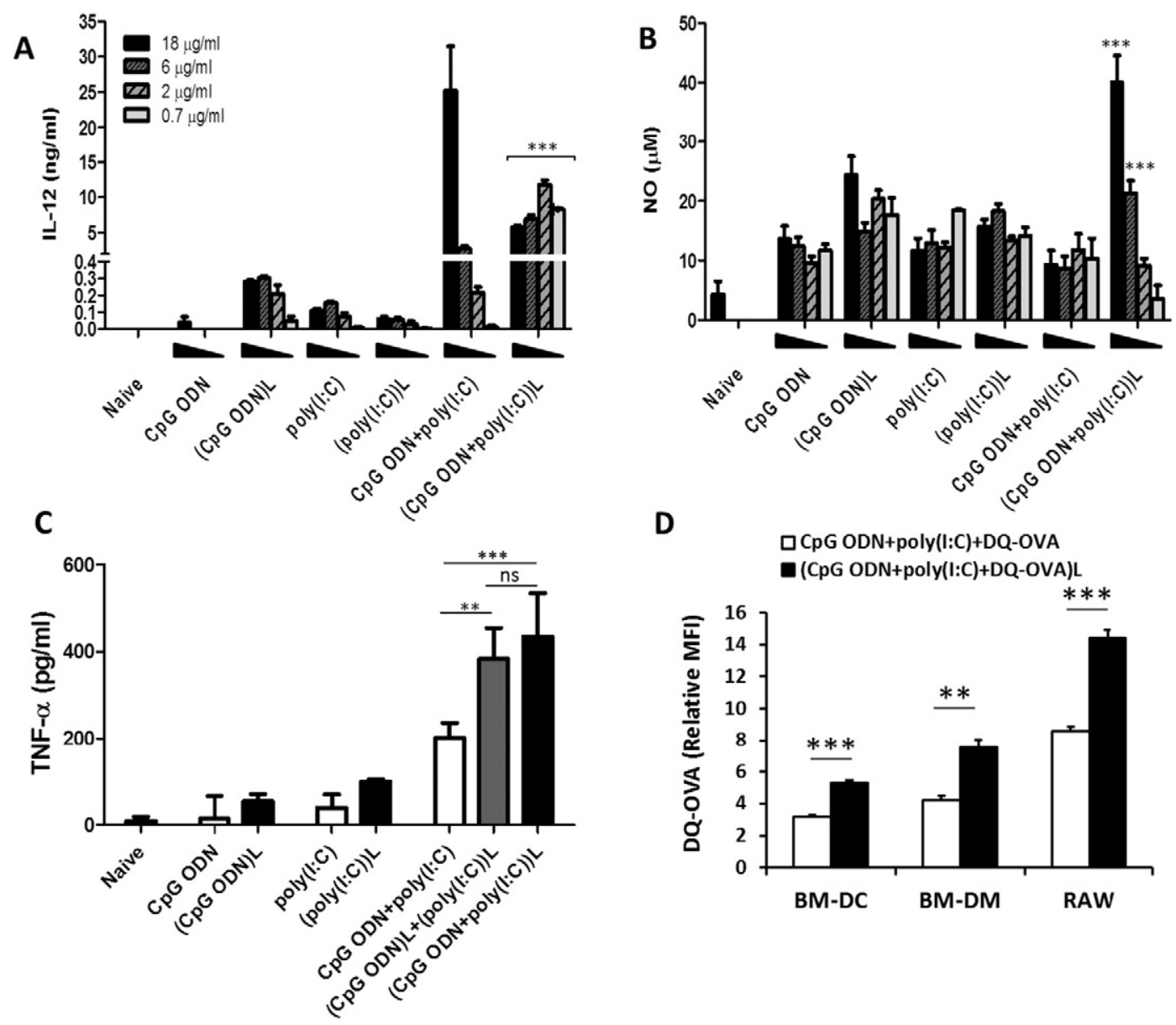

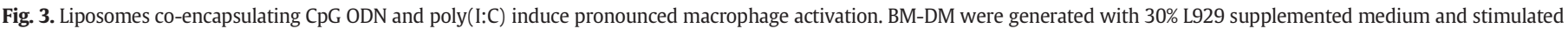

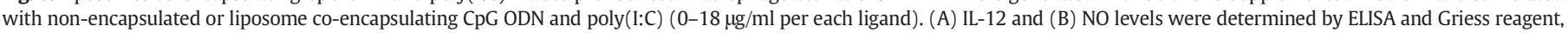

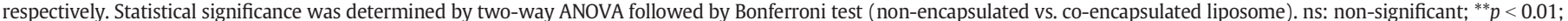

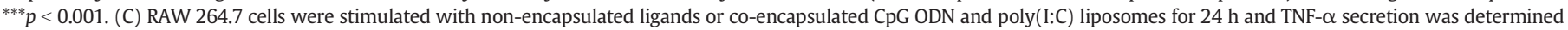

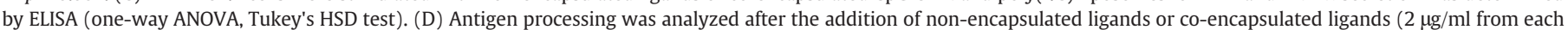

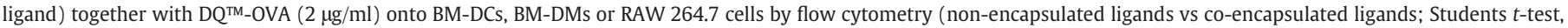
${ }^{*} p<0.05,{ }^{* *} p<0.01,{ }^{* * *} p<0.001$ ). Results are represented as average of two independent experiments done in triplicate (mean \pm SD).

considered, Only (CpG ODN + poly $(\mathrm{I}: \mathrm{C})+$ OVA)L group gave the highest IgG2c titers and lower IgG1 titer (compare Fig. 5C and D last three bars).

Collectively this data pointed out that antigen and dual adjuvants coencapsulated within liposomes achieved simultaneous antigen + adjuvant delivery to APC and triggered long-lasting, sustained anti-OVA specific Th1-biased immunity.

3.5. Vaccine formulations containing both $C p G O D N$ and poly $(\mathrm{I}: \mathrm{C})$ generated persisting memory $C D 8^{+} T$ cells and prevented tumor formation

We then sought whether OVA immune animals could effectively control or eradicate tumor inoculation. At the end of eight month post-booster injection, mice were subcutaneously (s.c.) inoculated with $4 \times 10^{6}$ E.G7 cells (EL4 cells transduced to express OVA) and were followed for 14 days. The individual tumor development was followed daily with electronic caliper. In all animals that were immunized with saline, tumor formation was observed 4 days post-E.G7 inoculation. The median of tumors in naive group reached $402.5 \mathrm{~mm}^{3}$. The tumor sizes at day 14 post-inoculation are presented in Fig. 6A. Animals immunized with liposomal formulations showed reduced tumor sizes. Mice that received $(\mathrm{CpG}$ ODN + poly $(\mathrm{I}: \mathrm{C})+\mathrm{OVA}) \mathrm{L}$ vaccine and challenged 8 months later gave $75 \%(n=6 / 8)$ tumor free animals at the end of $d=14$. All groups were significantly different than naive group (one-way ANOVA, $p<0.01$ ) and the variance between co-encapsulated group and independent ligands encapsulated liposome group were significantly different ( $F$ test, $p=0.0019$ ).

OVA specific memory T-cells is one of the major contributing cells to eliminate OVA-expressing tumor cells. The tumor specific $\mathrm{CD}^{+}{ }^{+} \mathrm{T}$-cell numbers were analyzed by IFN- $\gamma$ ELISPOT assay. The splenocytes from immunized animals were treated with $\mathrm{CD}^{+} \mathrm{T}$ cell specific OVA peptide (SIINFEKL) for $18 \mathrm{~h}$. The data revealed that co-administration of ligands + OVA to mice either with separately encapsulated or co-encapsulated liposomes significantly increased IFN $-\gamma^{+} \mathrm{CD} 8^{+} \mathrm{T}$ cell numbers (Fig. 6B). Surprisingly, (CpG ODN + poly (I:C) + OVA)L vaccine treated animals did not generate significantly higher $\mathrm{CC} 8+$ memory T-cell number compared to $(\mathrm{CPG}$ ODN + OVA $) \mathrm{L}+(\operatorname{poly}(\mathrm{I}: \mathrm{C})+\mathrm{OVA}) \mathrm{L}$ vaccine treated group.

Collectively, our findings implied that a combination of poly (I:C) and CpG ODN adjuvants in liposomal formulations induced stronger and persistent humoral and cellular anti-OVA specific immune response sufficient to eradicate tumors.

3.6. Synergistic immune activation elucidated in $\mathrm{hPBMCs}$ with liposomes co-encapsulating poly(I:C) and CpG ODN

In mice, due to strong in vivo anti-tumoral immune response generated upon co-encapsulated (CpG ODN $+\operatorname{poly}(\mathrm{I}: \mathrm{C})+$ OVA) 
A

Free Single Ligand

Liposome Loaded Single Ligand

Co-encapsulated

Separately Encapsulated

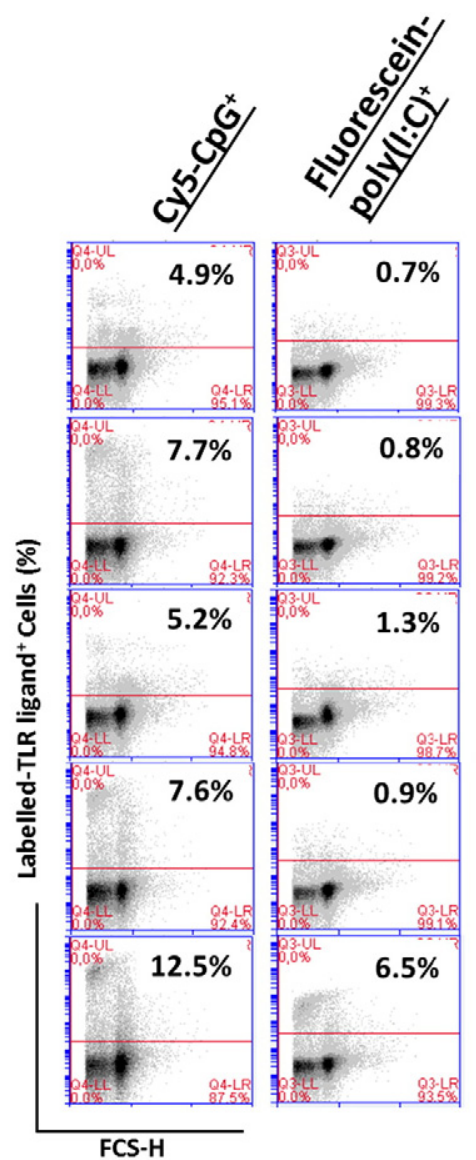

FCS-H

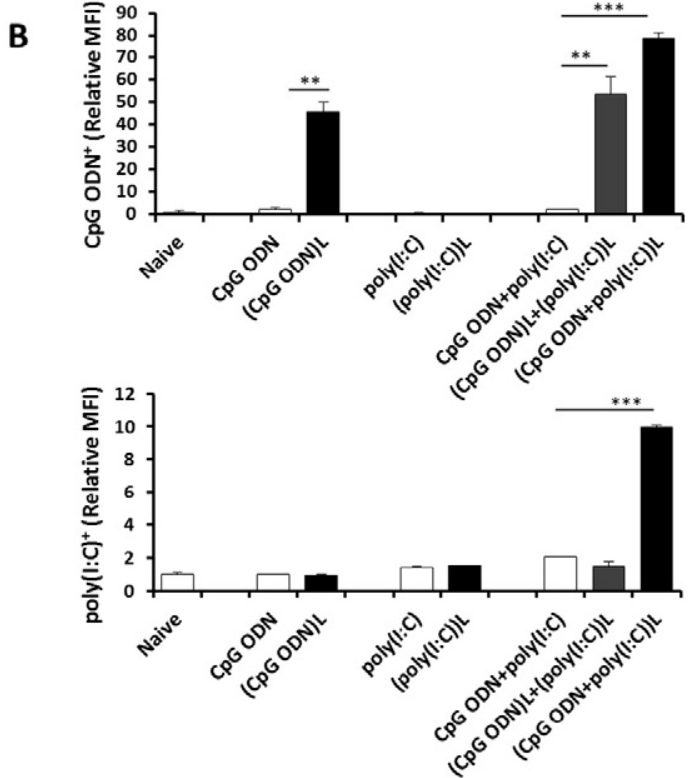

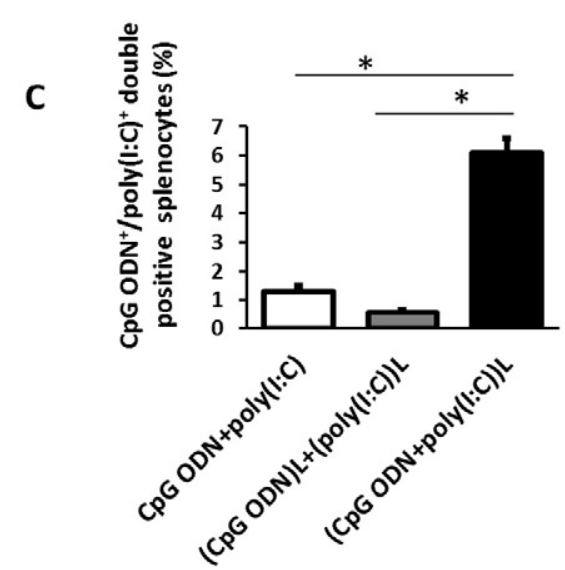

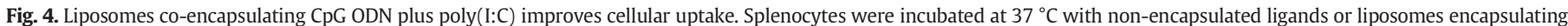

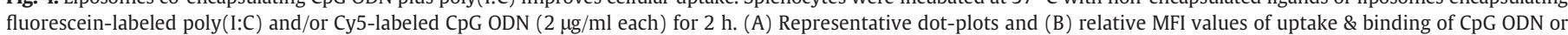

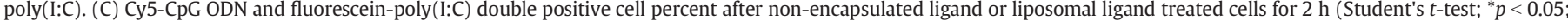
${ }^{* *} p<0.01 ;{ }^{* * *} p<0.001$ between groups). Data represents average of two independent experiments done in triplicate (mean \pm SD).

immunization, $75 \%$ of mice showed complete protection from tumor challenge. We next sought to establish whether this formulation triggers hPBMCs to the same extent that we observed in mice. Therefore, hPBMCs were collected from healthy donors and stimulated with i) non-encapsulated, ii) encapsulated and iii) co-encapsulated CpG ODN and/or poly(I:C) for $24 \mathrm{~h}$. All hPBMCs produced significantly higher levels of IFN- $\alpha$ (A, left panels) when treated with (CpG ODN + poly(I:C))L group. Similarly, the IP10 production was more with co-encapsulated liposomal group compared to non-encapsulated or separately encapsulated ligand combinations (Fig. 7A, right panels). In addition, percentages of $\mathrm{HLA}-\mathrm{DR}{ }^{+} / \mathrm{CD} 3^{+}{ }^{+}$hPBMCs were significantly higher in cells treated with dual ligands co-encapsulated into liposomes (one-way ANOVA, Tukey's HSD, $p<0.05$ between non-encapsulated vs co-encapsulation, and between separately vs co-encapsulation groups; Fig. 7B).
In conclusion, co-encapsulation of poly (I:C) and $\mathrm{CpG}$ ODN within liposomes enhanced secretion of interferon alpha and maturation of APCs in human immune cells. A promising finding implicating that these combinations could be translated to clinical applications.

\section{Discussion}

There is no doubt that TLR therapeutics soon will be in the clinics. The endosomal-associated TLR ligands senses nucleic acid ligands and are one of the most promising candidate bio-drugs as immunotherapeutic agents. Clinical trials harnessing various nucleic acid TLR ligands are underway aiming to cure diseases like cancer, allergy, autoimmune or autoinflammatory and infectious diseases. One of the promising area for TLR mediated therapeutics is to utilize them as vaccine adjuvants or immunoprotective agents where there is no available vaccines

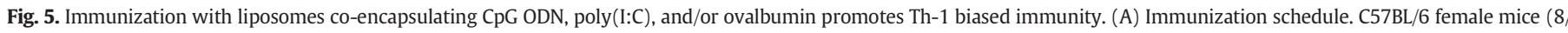

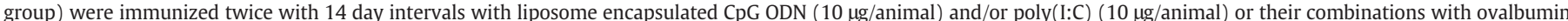

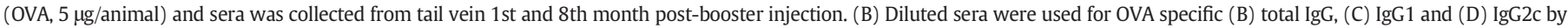
end-point ELISA (mean $\pm \mathrm{SD}$ ). Statistical significance was determined by one-way ANOVA followed by Tukey's (HSD) test. ns: non-significant; ${ }^{*} p<0.05 ;{ }^{* *} p<0.01$; ${ }^{* * *} p<0.001$. 
A

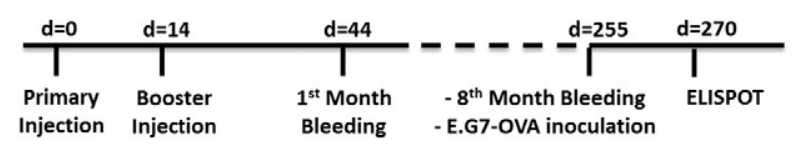

\section{B}
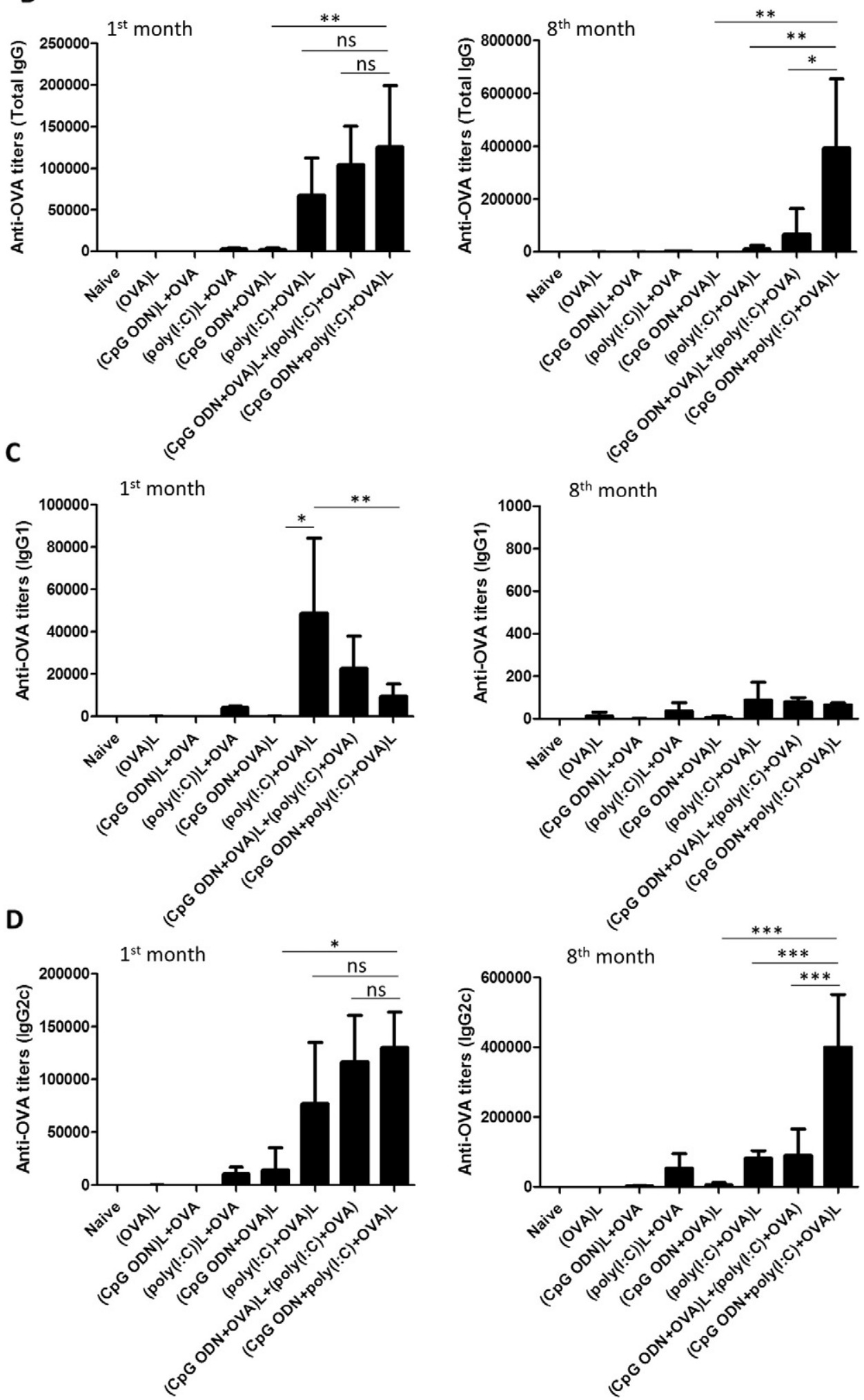
(including viral, bacterial and parasitic infections) $[8,16,18,19]$. Formulating these labile nucleic acid-based agents (i.e. ds RNA or CpG DNA) in stable form within proper depot systems improve their bioavailability and bioactivity at the of the target cell sites. We previously demonstrated that liposomes enhance in vivo immunostimulatory activity of TLR ligands along with ligand sparing effect and improved shelf-life [17,24, 26]. In this study, liposomes are used to co-encapsulate two important TLR ligands, expanding their breadth of synergistic immune activity, therefore, improving their immunoadjuvant effect upon co-encapsulating antigen of interest. Here, we provide evidence that these liposomes encapsulating dual TLR ligands i) upregulates costimulatory molecules, ii) magnifies proinflammatory and inflammatory cytokine secretion, iii) provides more efficient ligand internalization, iv) improves macrophage bactericidal activity v) boosts APC function of DCs and vi) promotes development of Th1 type immunity and vii) in mice provides long lasting antigen specific humoral and cell-mediated immunity capable of preventing E.G7 tumor development even after eight months postbooster injection.

Low doses of non-encapsulated single TLR ligand could be insufficient to mount an appreciable degree of immune activation however; combination of ligands even at low doses (here, $2 \mu \mathrm{g} / \mathrm{ml}$ of each ligand within liposomes) could trigger synergistic immune response when given within liposomes. Using MyD88 independent and dependent ligands trigger multiple signaling pathways improves the breadth of immune activation [30]. Krummen et al. demonstrated that the synergistic immunostimulatory action between TLR ligands was more pronounced than their standalone counterparts when MyD88 and TRIF-dependent signaling, like $\mathrm{CpG}$ ODN and poly(I:C), respectively, was combined [31]. In addition, studies showed the elevated immune response when CpG ODN is administered together with poly(I:C) [11-14,29,32]. We encapsulated these two ligands to enhance their synergistic activation and utilized them as novel form of long term effective anti-cancer vaccine. The demonstration of synergy between $\mathrm{CpG}$ ODN and poly(I:C) following co-encapsulation within liposomes were tested on murine splenocytes. Co-encapsulating CPG ODN plus poly(I:C) led to higher levels of secretion of type I and II IFNs, and IL-6 than non-encapsulated or loaded single or combinational ligands by splenocytes (Fig. 1). Co-encapsulation was stronger than separately encapsulated ligands. This improved activity suggested that co-encapsulating TLR3 and TLR9 ligands can activate immune response even better than their non-encapsulated combinations.

Additionally, type I IFN and IL-12 secretion was significantly elevated by co-encapsulation when compared with non-encapsulated or separately encapsulated dual ligands. Supporting our findings, it was shown that, IL-12 production from BM-DCs was synergistically increased with non-encapsulated combination [31,32]. However, in those studies, non-encapsulated poly(I:C) plus CpG ODN could not achieve to synergistically increase neither CD86 surface marker nor type I IFN secretion.

Liposomes act as a depot delivery system and improve cellular uptake of the ligands. Previously, we reported that uptake of CpG ODN is higher by immune cells when it is encapsulated within sterically stabilized cationic liposomes (SSCL) [26]. In this study, we showed that CpG ODN uptake was even higher when administered together with poly $(\mathrm{I}: \mathrm{C})$ into liposomes. More importantly, we provide evidence that dual uptake of ligands amplified sixfold more than non-encapsulated or separately encapsulated dual ligands (Fig. 4). In a study, lipofectamine mixed phosphorothioate-modified $\mathrm{CpG}$ ODN plus poly(I:C) was demonstrated to block uptake of poly(I:C) by tumor cells [34]. Here, since our ligands are encapsulated rather than complexed with the nanocarrier, we did not observe any blockage of wither of the ligand uptake. Besides, the uptake increase would be explained by the decreased size of liposomes co-encapsulating dual ligands compared to unloaded liposomes (Fig. S2).

Simultaneous presentation of adjuvants and antigen plays an important role in the quality and quantity of immune response against protein antigen [35,36]. Encapsulation of antigen with adjuvant within delivery vehicle overcomes random antigen and adjuvant uptake by APCs, furthermore it increases the internalization of exogenous antigen $[20,26$, 35-37]. We show that, higher IgG2c production was maintained over the course of 8 months only when mice were immunized with liposomes co-encapsulating antigen and adjuvants rather than standalone counterparts (Fig. 5).

In the present work, both co- and separately encapsulated groups protected immunized mice against tumor formation. However, when the content of the separately encapsulated liposome formulation, it contained two fold more antigen than co-encapsulated formulation (i.e. $(\mathrm{CpG}$ ODN + OVA $) \mathrm{L}+(\operatorname{poly}(\mathrm{I}: \mathrm{C})+$ OVA $) \mathrm{L}$ vs $\mathrm{CpG}$ ODN + poly $(\mathrm{I}: \mathrm{C})+\mathrm{OVA}) \mathrm{L})$. Therefore, it is important to note that co-encapsulated group yielded more pronounced Th1-biased anti-OVA immunity with 2-fold less antigen.

In a study, effect of lipid structure and size of DDA:TDB liposomes were investigated on cellular and humoral responses and CpG ODN and/or poly(I:C) were co-encapsulated or complexed to enhance immunogenicity of liposomes. Results revealed that co-encapsulating dual ligands into DDA:TDB liposomes boosted total IgG and induced Agspecific T cell activation in multilamellar vesicles (MLV) not in SUV [37]. In that study, three immunizations with $250 \mu \mathrm{g}$ DDA:DSPC, $50 \mu \mathrm{g}$ TDB, $20 \mu \mathrm{g}$ CpG, $50 \mu \mathrm{g}$ poly(I:C) and $20 \mu \mathrm{g}$ OVA were employed for every injection. As DDA:TDB liposomes have immunogenic effect by its own [38], Our vaccine candidate composed of $10 \mu \mathrm{g} \mathrm{CpG}, 10 \mu \mathrm{g}$ poly $(\mathrm{I}: \mathrm{C})$, and $5 \mu \mathrm{g}$ OVA, in neutral liposomes is the first study demonstrating enhanced synergy of $\mathrm{CpG} O \mathrm{ODN}$ and poly $(\mathrm{I}: \mathrm{C})$ when co-encapsulated into non-immunogenic liposomes (Fig. S3) together with antigen that with immunization, both Th1 and CTL responses were sustained over the course of 8 months, and successfully protects immunized mice to develop tumors. The aim of the present study is to develop a cancer vaccine that can protect individuals long after they are vaccinated against a specific cancer antigen. It is true that much shorter tumor challenge intervals are used for therapeutic vaccinations. However, CpG ODN and poly (I:C) is known to mediate antigen independent clearance of tumor cells. In this study, since we aimed to address the contribution of memory CD8 + T-cells, we chose to challenge our animals eight month after booster injection, therefore, TLR ligands mediated non-specific innate immune activation could not be responsible from tumor elimination.

\section{Conclusion}

Liposomes co-encapsulating CpG ODN and poly(I:C) boosted cellular uptake of the cargo, improved proinflammatory cytokine production along with type I/II IFN secretion, as well as co-stimulatory molecule upregulation leading to a pronounced APC function and antigen processing. The co-encapsulation of OVA antigen into liposome vesicles created a long-lasting anti-cancer immune response. The heightened Th1 immunity in addition to enhanced OVA-specific memory $\mathrm{CD}^{+} \mathrm{T}$ cell response helped to control tumor development. Similar immune stimulatory activity was reproduced with human peripheral mononuclear cells, supporting the applicability for human use. In conclusion, the present liposomal vaccine candidate offers an effective antigen and adjuvants co-encapsulation approach and could be developed as preventive vaccine for human use against cancer or viral diseases.

\section{Conflict of interest}

The authors confirm that there are no known conflicts of interest associated with this publication and there has been no significant financial support for this work that could have influenced its outcome. 
A
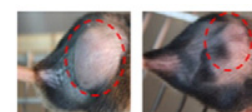

$n=8 / 8$

$5 / 8$
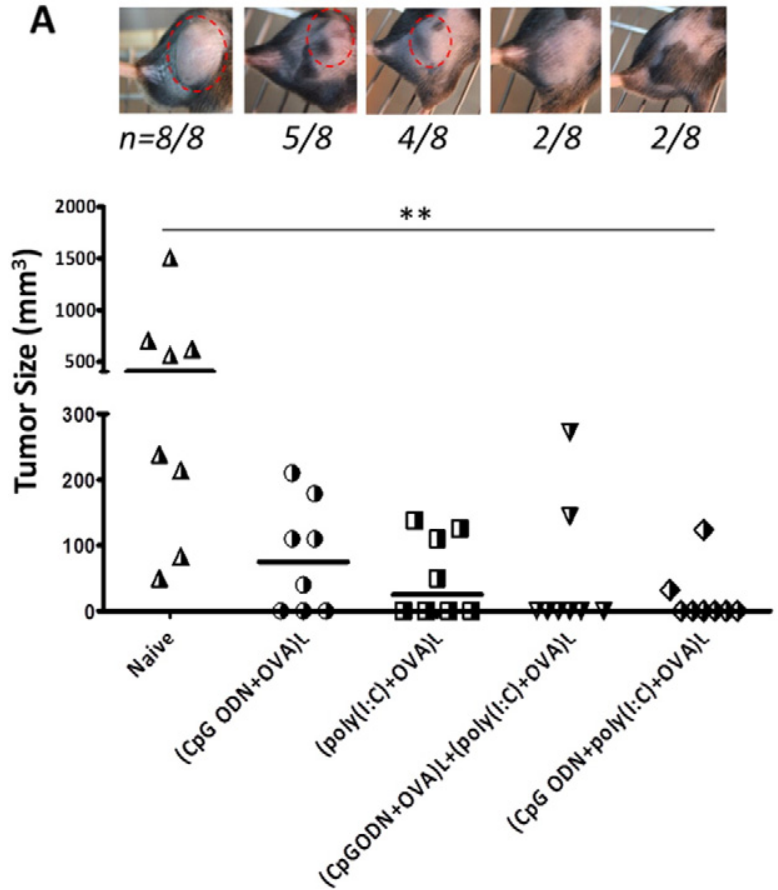

B

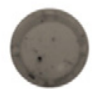

(i)
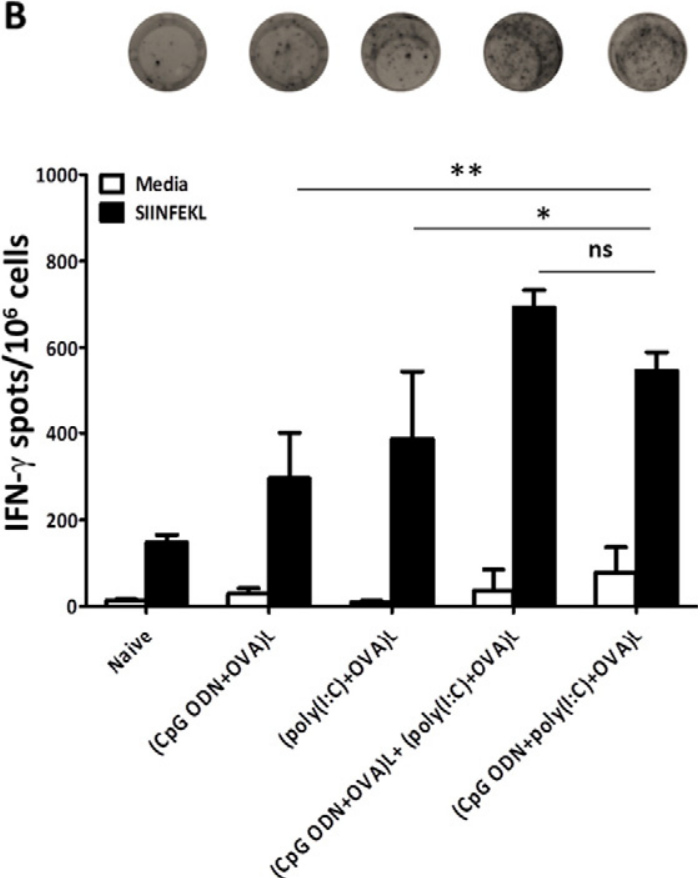

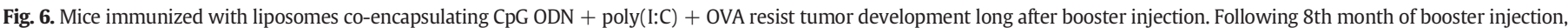

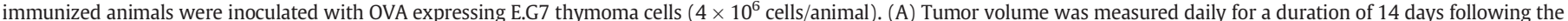

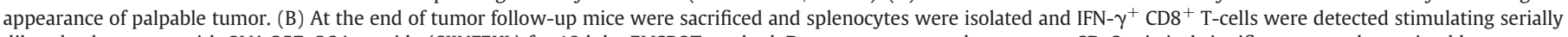

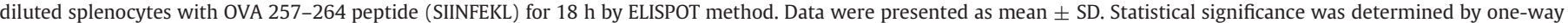
ANOVA followed by Tukey's (HSD) test. ns: non-significant; ${ }^{*} p<0.05 ;{ }^{* *} p<0.01,{ }^{* * * *} p<0.001$.

\section{A IFN- $\alpha(\mathrm{ng} / \mathrm{ml}) \quad$ IP-10 $(\mathrm{ng} / \mathrm{ml})$}

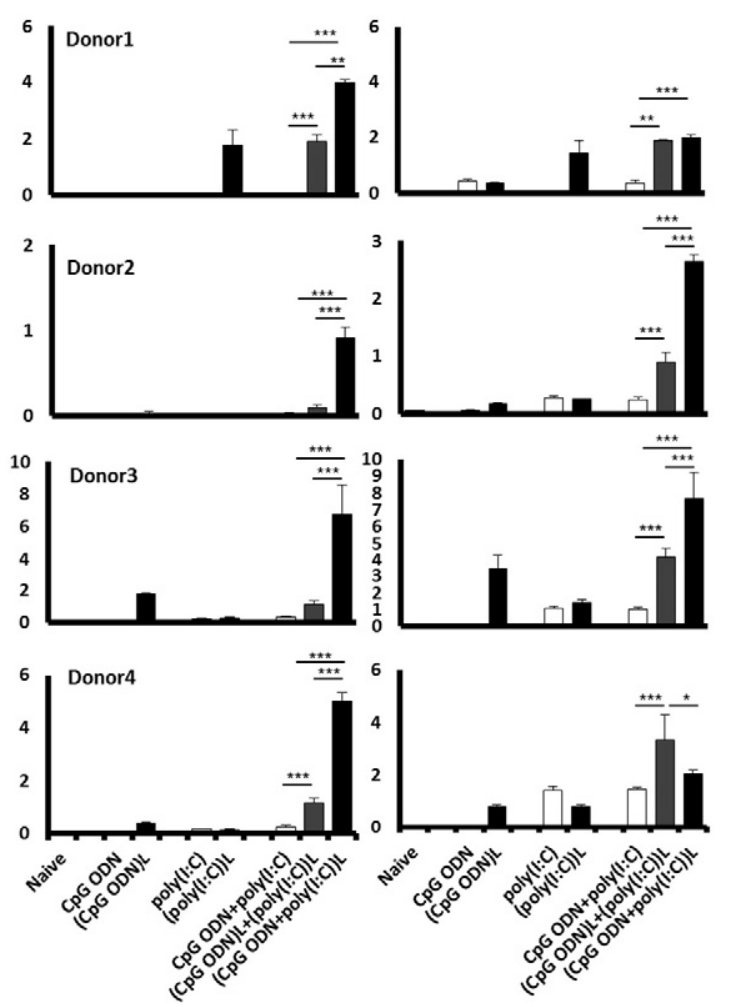

B

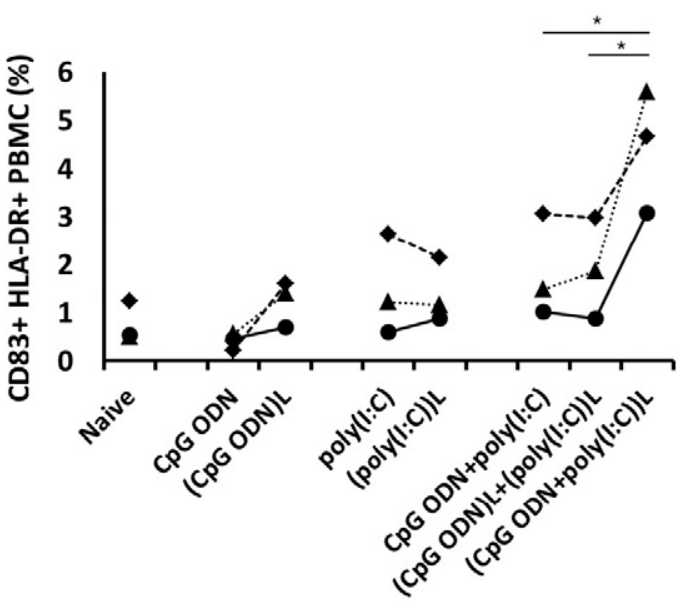

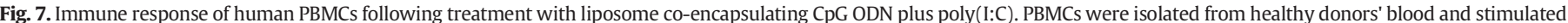

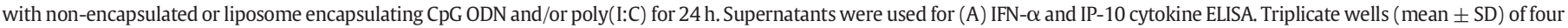

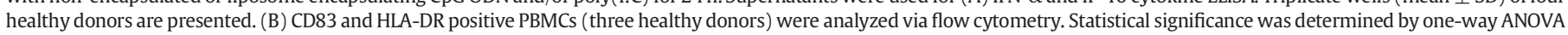
followed by Tukey's (HSD) test. ns: non-significant; ${ }^{*} p<0.05 ;{ }^{* *} p<0.01 ;{ }^{* * *} p<0.001$. 


\section{Acknowledgements}

This work was partly supported by the Scientific and Technological Research Council of Turkey grants \#: SBAG113S207 to IG.

\section{Appendix A. Supplementary data}

Supplementary data to this article can be found online at http://dx. doi.org/10.1016/j.jconrel.2017.01.004.

\section{References}

[1] C.A. Janeway, R. Medzhitov, Innate immune recognition, Annu. Rev. Immunol. 20 (2002) 197-216, http://dx.doi.org/10.1146/annurev.immunol.20.083001.084359.

[2] D. Schenten, R. Medzhitov, The control of adaptive immune responses by the innate immune system, Adv. Immunol. 109 (2011) 87-124, http://dx.doi.org/10.1016/ B978-0-12-387664-5.00003-0.

[3] L. Alexopoulou, A.C. Holt, R. Medzhitov, R.A. Flavell, Recognition of double-stranded RNA and activation of NF-kappaB by toll-like receptor 3, Nature 413 (2001) 732-738, http://dx.doi.org/10.1038/35099560.

[4] F. Heil, H. Hemmi, H. Hochrein, F. Ampenberger, C. Kirschning, S. Akira, G. Lipford, H. Wagner, S. Bauer, Species-specific recognition of single-stranded RNA via toll-like receptor 7 and 8, Science 303 (2004) 1526-1529, http://dx.doi.org/10.1126/ science. 1093620.

[5] F. Takeshita, C.A. Leifer, I. Gursel, K.J. Ishii, S. Takeshita, M. Gursel, D.M. Klinman, Cutting edge: role of toll-like receptor 9 in CpG DNA-induced activation of human cells, J. Immunol. 167 (2001) 3555-3558 (http://www.ncbi.nlm.nih.gov/pubmed/ 11564765 accessed November 24, 2014).

[6] T. Kawai, S. Akira, The role of pattern-recognition receptors in innate immunity: update on toll-like receptors, Nat. Immunol. 11 (2010) 373-384, http://dx.doi.org/10. 1038/ni.1863.

[7] R.S.T. Tan, B. Ho, B.P. Leung, J.L. Ding, TLR cross-talk confers specificity to innate immunity, Int. Rev. Immunol. 33 (2014) 443-453, http://dx.doi.org/10.3109/ 08830185.2014.921164.

[8] D.M. Klinman, D. Currie, I. Gursel, D. Verthelyi, Use of CpG oligodeoxynucleotides as immune adjuvants, Immunol. Rev. 199 (2004) 201-216, http://dx.doi.org/10.1111/j. 0105-2896.2004.00148.x.

[9] D. Verthelyi, KJ. Ishii, M. Gursel, F. Takeshita, D.M. Klinman, Human peripheral blood cells differentially recognize and respond to two distinct CPG motifs, J. Immunol. 166 (2001) 2372-2377, http://dx.doi.org/10.4049/jimmunol.166.4.2372.

[10] V. Gosu, S. Basith, O.-P. Kwon, S. Choi, Therapeutic applications of nucleic acids and their analogues in toll-like receptor signaling, Molecules 17 (2012) 13503-13529, http://dx.doi.org/10.3390/molecules171113503.

[11] D. Kim, S. Niewiesk, Synergistic induction of interferon $\alpha$ through TLR-3 and TLR-9 agonists identifies CD21 as interferon $\alpha$ receptor for the B cell response, PLoS Pathog. 9 (2013), e1003233. http://dx.doi.org/10.1371/journal.ppat.1003233.

[12] H. He, K.M. MacKinnon, K.J. Genovese, M.H. Kogut, CpG oligodeoxynucleotide and double-stranded RNA synergize to enhance nitric oxide production and mRNA expression of inducible nitric oxide synthase, pro-inflammatory cytokines and chemokines in chicken monocytes, Innate Immun. 17 (2011) 137-144, http://dx. doi.org/10.1177/1753425909356937.

[13] C. Grossmann, M. Tenbusch, G. Nchinda, V. Temchura, G. Nabi, G.W. Stone, R.S Kornbluth, K. Überla, Enhancement of the priming efficacy of DNA vaccines encoding dendritic cell-targeted antigens by synergistic toll-like receptor ligands, BMC Immunol. 10 (2009) 43, http://dx.doi.org/10.1186/1471-2172-10-43.

[14] M.M. Whitmore, Synergistic activation of innate immunity by double-stranded RNA and CpG DNA promotes enhanced antitumor activity, Cancer Res. 64 (2004) 5850-5860, http://dx.doi.org/10.1158/0008-5472.CAN-04-0063.

[15] H. Ishizaki, G.-Y. Song, T. Srivastava, K.D. Carroll, V. Shahabi, E.R. Manuel, D.J. Diamond, J.D.I. Ellenhorn, Heterologous prime/boost immunization with p53based vaccines combined with toll-like receptor stimulation enhances tumor regression, J. Immunother. 33 (2010) 609-617, http://dx.doi.org/10.1097/CJI. 0b013e3181e032c6.

[16] M.S. Duthie, H.P. Windish, C.B. Fox, S.G. Reed, Use of defined TLR ligands as adjuvants within human vaccines, Immunol. Rev. 239 (2011) 178-196, http://dx.doi. org/10.1111/j.1600-065X.2010.00978.x.

[17] K.J. Ishii, K. Kawakami, I. Gursel, J. Conover, B.H. Joshi, D.M. Klinman, R.K. Puri, Antitumor therapy with bacterial DNA and toxin: complete regression of established tumor induced by liposomal CpG oligodeoxynucleotides plus interleukin-13 cytotoxin, Clin. Cancer Res. 9 (2003) 6516-6522 (http://clincancerres.aacrjournals.org/ content/9/17/6516.short (accessed November 24, 2014)).

[18] D.E. Fonseca, J.N. Kline, Use of CpG oligonucleotides in treatment of asthma and allergic disease, Adv. Drug Deliv. Rev. 61 (2009) 256-262, http://dx.doi.org/10.1016/j. addr.2008.12.007.
[19] M.E. Barry, D. Pinto-González, F.M. Orson, G.J. McKenzie, G.R. Petry, M.A. Barry, Role of endogenous endonucleases and tissue site in transfection and $\mathrm{CpG}$-mediated immune activation after naked DNA injection, Hum. Gene Ther. 10 (1999) 2461-2480, http://dx.doi.org/10.1089/10430349950016816.

[20] S.P. Kasturi, I. Skountzou, R.A. Albrecht, D. Koutsonanos, T. Hua, H.I. Nakaya, R. Ravindran, S. Stewart, M. Alam, M. Kwissa, F. Villinger, N. Murthy, J. Steel, J. Jacob, R.J. Hogan, A. García-Sastre, R. Compans, B. Pulendran, Programming the magnitude and persistence of antibody responses with innate immunity, Nature 470 (2011) 543-547, http://dx.doi.org/10.1038/nature09737.

[21] H. Xie, I. Gursel, B.E. Ivins, M. Singh, D.T. O'Hagan, J.B. Ulmer, D.M. Klinman, CpC oligodeoxynucleotides adsorbed onto polylactide-co-glycolide microparticles improve the immunogenicity and protective activity of the licensed anthrax vaccine Infect. Immun. 73 (2005) 828-833, http://dx.doi.org/10.1128/IAI.73.2.828-833. 2005.

[22] G. Tincer, S. Yerlikaya, F.C. Yagci, T. Kahraman, O.M. Atanur, O. Erbatur, I. Gursel, Immunostimulatory activity of polysaccharide-poly(I:C) nanoparticles, Biomaterials 32 (2011) 4275-4282, http://dx.doi.org/10.1016/j.biomaterials.2011.01.028.

[23] K.D. Wilson, S.D. de Jong, Y.K. Tam, Lipid-based delivery of CpG oligonucleotides enhances immunotherapeutic efficacy, Adv. Drug Deliv. Rev. 61 (2009) 233-242, http://dx.doi.org/10.1016/j.addr.2008.12.014.

[24] E. Erikçi, M. Gursel, I. Gursel, Differential immune activation following encapsulation of immunostimulatory $\mathrm{CpG}$ oligodeoxynucleotide in nanoliposomes, Biomaterials 32 (2011) 1715-1723, http://dx.doi.org/10.1016/j.biomaterials.2010.10.054

[25] K. Zaks, M. Jordan, A. Guth, K. Sellins, R. Kedl, A. Izzo, C. Bosio, S. Dow, Efficient immunization and cross-priming by vaccine adjuvants containing TLR3 or TLR9 agonists complexed to cationic liposomes, J. Immunol. 176 (2006) 7335-7345, http:// dx.doi.org/10.4049/jimmunol.176.12.7335.

[26] I. Gursel, M. Gursel, K.J. Ishii, D.M. Klinman, Sterically stabilized cationic liposomes improve the uptake and immunostimulatory activity of $\mathrm{CpG}$ oligonucleotides, J. Immunol. 167 (2001) 3324-3328, http://dx.doi.org/10.4049/jimmunol.167.6.3324.

[27] D. Verthelyi, R.T. Kenney, R.A. Seder, A.A. Gam, B. Friedag, D.M. Klinman, CpC oligodeoxynucleotides as vaccine adjuvants in primates, J. Immunol. 168 (2002) 1659-1663, http://dx.doi.org/10.4049/jimmunol.168.4.1659.

[28] S. Yildiz, E. Alpdundar, B. Gungor, T. Kahraman, B. Bayyurt, I. Gursel, M. Gursel, Enhanced immunostimulatory activity of cyclic dinucleotides on mouse cells when complexed with a cell-penetrating peptide or combined with CpG, Eur. J. Immunol. 1170-1179 (2015)http://dx.doi.org/10.1002/eji.201445133.

[29] D. Tross, L. Petrenko, S. Klaschik, Q. Zhu, D.M. Klinman, Global changes in gene expression and synergistic interactions induced by TLR9 and TLR3, Mol. Immunol. 46 (2009) 2557-2564, http://dx.doi.org/10.1016/j.molimm.2009.05.011.

[30] A. Bagchi, E. Herrup, MyD88-dependent and MyD88-independent pathways in synergy, priming, and tolerance between TLR agonists, J. Immunol. 178 (2007) 1164-1171 (http://www.jimmunol.org/content/178/2/1164 accessed October 22, 2014).

[31] M. Krummen, S. Balkow, L. Shen, S. Heinz, C. Loquai, H.-C. Probst, S. Grabbe, Release of IL-12 by dendritic cells activated by TLR ligation is dependent on MyD88 signaling, whereas TRIF signaling is indispensable for TLR synergy, J. Leukoc. Biol. 88 (2010) 189-199, http://dx.doi.org/10.1189/jlb.0408228.

[32] Q. Zhu, C. Egelston, A. Vivekanandhan, S. Uematsu, S. Akira, D.M. Klinman, I.M Belyakov, J.A. Berzofsky, Toll-like receptor ligands synergize through distinct dendritic cell pathways to induce T cell responses: implications for vaccines, Proc. Natl. Acad. Sci. 105 (2008) 16260-16265, http://dx.doi.org/10.1073/pnas. 0805325105

[34] Y. Zhang, A. Lin, Q. Sui, C. Zhang, Z. Tian, J. Zhang, Phosphorothioate modification of the TLR9 ligand CPG ODN inhibits poly(I:C)-induced apoptosis of hepatocellular carcinoma by entry blockade, Cancer Lett. 355 (2014) 76-84, http://dx.doi.org/10 1016/j.canlet.2014.09.013.

[35] A. Heit, F. Schmitz, T. Haas, D.H. Busch, H. Wagner, Antigen co-encapsulated with adjuvants efficiently drive protective T cell immunity, Eur. J. Immunol. 37 (2007) 2063-2074, http://dx.doi.org/10.1002/eji.200737169.

[36] E. Schlosser, M. Mueller, S. Fischer, S. Basta, D.H. Busch, B. Gander, M. Groettrup, TLR ligands and antigen need to be coencapsulated into the same biodegradable microsphere for the generation of potent cytotoxic T lymphocyte responses, Vaccine 26 (2008) 1626-1637, http://dx.doi.org/10.1016/j.vaccine.2008.01.030.

[37] A. Milicic, R. Kaur, A. Reyes-Sandoval, C.K. Tang, J. Honeycutt, Y. Perrie, A.V.S. Hill, Small cationic DDA:TDB liposomes as protein vaccine adjuvants obviate the need for tlr agonists in inducing cellular and humoral responses, PLoS One 7 (2012) 1-10, http://dx.doi.org/10.1371/journal.pone.0034255.

[38] J. Davidsen, I. Rosenkrands, D. Christensen, A. Vangala, D. Kirby, Y. Perrie, E.M. Agger P. Andersen, Characterization of cationic liposomes based on dimethyldioctadecylammonium and synthetic cord factor from M. tuberculosis (trehalose 6,6'-dibehenate)-a novel adjuvant inducing both strong CMI and antibody responses, Biochim. Biophys. Acta Biomembr. 1718 (2005) 22-31, http://dx.doi. org/10.1016/j.bbamem.2005.10.011. 